\title{
Thiol-Methylsulfone based Hydrogels: Enhanced Control on Gelation Kinetics for 3D Cell Encapsulation
}

\author{
Julieta I. Paez, * Aleeza Farrukh, Małgorzata K. Włodarczyk-Biegun, Aránzazu del Campo*
}

Dr. Julieta I. Paez, Dr. Aleeza Farrukh, Dr. Małgorzata K. Włodarczyk-Biegun, Prof. Dr. Aránzazu del Campo.

INM - Leibniz Institute for New Materials, Campus D2-2, 66123, Saarbrücken, Germany

E-mail: julieta.paez@leibniz-inm.de; aranzazu.delcampo@leibniz-inm.de

Prof. Dr. Aránzazu del Campo.

Saarland University, Chemistry Department, 66123 Saarbrücken, Germany

Keywords: 3D cell culture, thiol-mediated chemistry, coupling under physiological conditions, aromatic methylsulfones, gelation kinetics.

\footnotetext{
Abstract: Hydrogels are useful temporal matrices for cell culture technologies. The successful mixing and encapsulation of cells within the gel requires the selection of efficient and cytocompatible gelation reactions occurring in the minute timescale under physiological conditions. The thiol-methylsulfonyl (MS) chemical reaction is introduced here as a novel chemistry to encapsulate cells in polymeric matrices. Thiol-MS crosslinking does not require a light activation step and can occur within the seconds-to-minutes timescale by adjusting the $\mathrm{pH}$ in the physiological range 8.0-6.6. This reaction is cytocompatible and the reaction product is hydrolytically stable in cell culture media up to 4 weeks. Cell encapsulation protocols enabling comfortable handling and yielding homogenous distribution of the embedded cells are described. All these features are relevant for the application of this crosslinking reaction to biomedical scenarios. Finally, this manuscript also compares the performance of thiol-MS hydrogels with the established thiol-maleimide and thiolvinylsulfone hydrogels. The benefit of thiol-MS crosslinking in terms of control over hydrogelation kinetics is demonstrated.
} 


\section{Introduction}

Progress in 3D culture technologies and cell therapies depends on our ability to encapsulate cells in supportive microenvironments for cellular proliferation and self-organization. Hydrogels are typically used as temporal extracellular matrix substituents in these application scenarios. A major challenge here is the development of crosslinking and biofunctionalization strategies that are efficient under physiological conditions and do not impair function of the encapsulated cells. ${ }^{[1]}$ Additional requirements for practical application are simple handling, stability of precursors and crosslinked products, orthogonality to common backbone functionalities of clinically approved polymers, and tunable crosslinking kinetics to be adaptable to the particular application. A number of reactive chemistries for crosslinking under physiological conditions are nowadays available: radical-mediated acrylic polymerization, ${ }^{[2]}$ amine-NHS ester coupling, ${ }^{[3]}$ Schiff-base formation, ${ }^{[4]}$ cycloadditions (including strain-promoted azide-cycloalkyne, ${ }^{[5]}$ normal $^{[6]}$ and inverse ${ }^{[7]}$ electron demand Diels Alder), mussel-bioinspired catechol oxidation, ${ }^{[8]}$ native chemical ligation, ${ }^{[9]}$ radicalmediated thiol-ene ${ }^{[10]}$ and thiol-yne, ${ }^{[11]}$ and nucleophilic Michael-additions. ${ }^{[12]}$ However, none of these options fulfils all the previously mentioned criteria.

Thiol-mediated chemistry has become popular for crosslinking and preparing cell-laden hydrogels. ${ }^{[13]}$ Thiols can react with activated alkenes or alkynes (thiol-ene/yne) by means of photogenerated radicals (with acrylate and norbornene groups) or through polar Michael additions (with acrylates, maleimides (Mal), and vinyl sulfones (VS)). However, photoactivated thiol-ene crosslinking has some limitations for use in combination with cells. ${ }^{[12 c]}$ Photodamage suffered by cells and the lack of transparency of natural tissues pose technical limitations to the application of this strategy in real scenarios. Thiol-Mal ${ }^{[12 \mathrm{~b}]}$ and thiol-VS ${ }^{[12 \mathrm{a}]}$ coupling reactions do not require light activation. ${ }^{[14]}$ However, crosslinking begins immediately upon mixing of the two components, and the reaction kinetics becomes a 
critical parameter for the cell encapsulation step. The reaction should be slow enough to allow mixing and homogenization of the reactive precursors and the cells at low shear forces, and fast enough to reduce environmental stress and to avoid sedimentation of embedded cells. ${ }^{[15]}$ Comfortable crosslinking times are between 30 seconds and a few minutes. ${ }^{[16]}$ Thiol-Mal reaction has a very fast rate constant (see Table 1) and thiol-Mal hydrogels form within a few seconds. It has been reported that this leads to inhomogeneity of the hydrogel matrix, and lowers reproducibility in the cell response. ${ }^{[17]}$ Additionally, the Mal precursor is prone to hydrolysis under mild basic conditions, and the thiol-Mal adduct (thioether succinimide linkage) undergoes retro-Michael and exchange reactions in presence of other thiols existing in culture media. ${ }^{[18]}$ As consequence, gel stability cannot be maintained for long culture times. Conversely, the thiol-VS system is very stable towards hydrolysis: both VS precursor and thioether adduct are stable for long time under physiological conditions. ${ }^{[13 c]}$ However, thiolVS coupling rate constant is 2-3 orders of magnitude slower than thiol-Mal. In fact, thiol-VS hydrogels form within several minutes to hours. Therefore, although the reactive VS-system can be properly mixed, cell sedimentation and clustering are commonly observed. ${ }^{[19]}$ This precludes homogeneous distribution of the encapsulated cells throughout the material. Several approaches have been tested to narrow the "kinetic gap" between the thiol-Mal and thiol-VS reactions, either by changing reaction conditions (temperature, $\mathrm{pH}$, buffer type and concentration, presence of catalysts or inhibitors) $;{ }^{[17,20]}$ or by changing the concentration ${ }^{[17 b \text {, }}$ ${ }^{20 \mathrm{a}]}$ or architecture of the polymer precursor (molar mass, branching, multifunctionality). ${ }^{[19-20 \text {, }}$ ${ }^{21]}$ Other approaches include the tuning of the reaction rate by molecularly engineering the pKa of the thiol group ${ }^{[17,20 a]}$ (changing the thiol's molecular environment) and the use of thickeners to adjust the viscosity of gel precursors to prevent cell sedimentation. ${ }^{[22]}$ Despite the progress so far, kinetic control of these systems may come at the expenses of changes in the mechanical properties of the final hydrogel, or compromised cell viability. For example, decreasing $\mathrm{pH}$ from 8 to 5 allowed to increase the gelation time of thiol-Mal from a few 
seconds to roughly one minute; albeit with a consequent 3-fold drop of the final shear modulus G'. ${ }^{[17 b]}$ Moreover, $16 \mathrm{mM}$ zinc chloride was added to inhibit and slow down the thiol-Mal gelation to 2-3 min; however, the needed concentration of this compound proved to be non-cytocompatible. ${ }^{[17 b]}$

The thiol-methylsulfonyl (MS) reaction is an interesting alternative to thiol-Mal or thiol-VS reactions which has not been exploited for crosslinking hydrogels so far. Thiols effectively react with aromatic rings bearing MS groups under physiological conditions via a nucleophilic aromatic substitution mechanism. ${ }^{[23]}$ This reaction is characterized by high yield, high chemoselectivity and the formation of a stable thio-ether product. ${ }^{[23 a]}$ Moreover, its reaction rate can be regulated by adjusting the $\mathrm{pH}$ in the range $6-9^{[23 \mathrm{a}]}$ and by adjusting the electron-deficient character of the aromatic substrate bearing the MS group. ${ }^{[23 b, 24]}$ This reaction, originally developed for the selective blocking of thiol-containing proteins ${ }^{[23 \mathrm{a}]}$ and for protein bioconjugation, ${ }^{[23 b]}$ has been recently applied by our group to biofunctionalize hydrogels for $2 \mathrm{D}$ cell culture. ${ }^{[25]}$ The observed high reaction conversion and moderate reaction rate ${ }^{[24]}$ of the thiol-MS chemistry as well as the good stability ${ }^{[23]}$ and proven cytocompatibility $^{[25 \mathrm{a}]}$ of formed adducts are ideal properties for crosslinking cell-laden hydrogels. In this manuscript we study the crosslinking kinetics of thiol-MS derived poly(ethylene glycol) (PEG), and demonstrate its benefits $v s$. thiol-Mal and thiol-VS systems for cell encapsulation. 
Table 1. Reported second-order reaction rate constants for selected nucleophilic thiol-X couplings under mild aqueous conditions.

\begin{tabular}{|c|c|c|}
\hline $\mathrm{X}$ react. group & reaction rate $k_{2}\left[\mathrm{M}^{-1} \mathrm{~s}^{-1}\right]$ & reference \\
\hline Mal & 734.0 & [26] \\
\hline MS & $0.4-16.0$ & [24] \\
\hline VS & $0.08-1.0$ & [2/] \\
\hline
\end{tabular}

\section{Results and Discussion}

We selected the 2-(methylsulfonyl)-5-phenyl-1,3,4-oxadiazole group as MS substrate for thiol coupling. Among reported MS heteroaromatic rings, this substrate reacts with thiols with high conversion at intermediate reaction rate (Table 1). ${ }^{\left[23 \mathrm{~b},{ }^{24]}\right.} 4$-arm PEG-MS macromers $(20 \mathrm{kDa})$ with substitution degree $>95 \%$ were synthesized at 350 -mg scale in good yield after three simple synthetic steps to form two amide bonds (Figure 1a). The MS precursor carrying an aromatic amine was first coupled to Boc-glycine followed by Boc deprotection and coupling to PEG-NHS. Details on the synthesis, purification and characterization of intermediates and macromers are included in the Supporting Information (SI). 

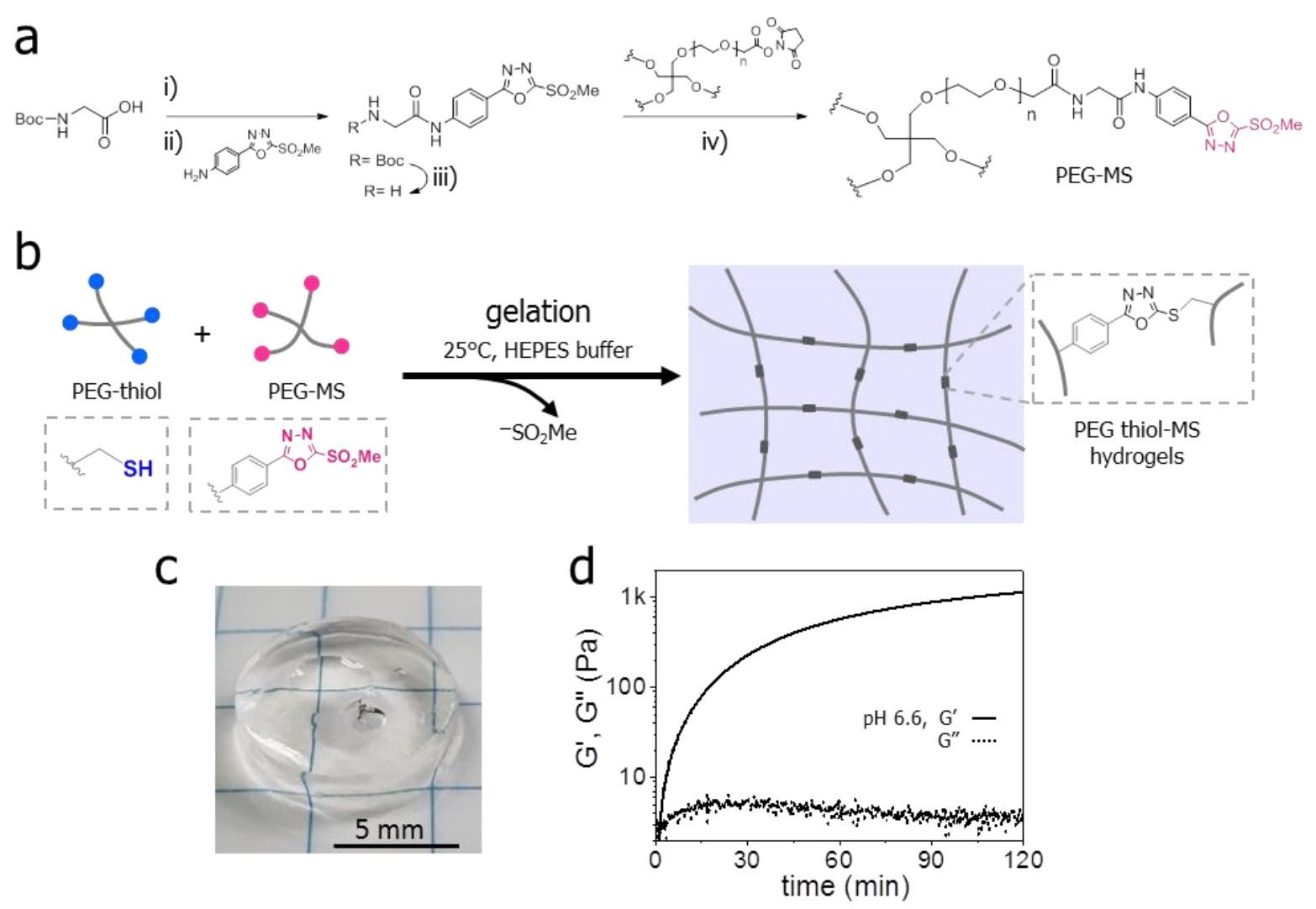

Figure 1. Chemical structure and properties of PEG-based thiol-MS hydrogels. a) Synthetic pathway to PEG-MS macromer; conditions: i) isobutyl chloformate, NMM, THF:DMF (1:1), $0^{\circ} \mathrm{C}, 30 \mathrm{~min}$; ii) r.t, overnight; iii) TFA:DCM (1:1), $0^{\circ} \mathrm{C}, 30 \mathrm{~min}$; iv) DMF, NMM, r.t, $\mathrm{N}_{2}$, overnight. b) Schematic crosslinking of PEG-MS and PEG-thiol precursors to form PEGthiol-MS hydrogels. c) Photograph of a swollen PEG-thiol-MS hydrogel. d) Shear storage $\left(G^{\prime}\right)$ and loss (G') moduli as a function of time during gel formation. Conditions for c-d): 5 wt $\%$ polymer, $10 \mathrm{mM}$ HEPES buffer $\mathrm{pH} 6.6, T=25^{\circ} \mathrm{C}$.

The gelation of 4-arm PEG-MS and 4-arm PEG-thiol mixture was explored. Applied crosslinking conditions were $5 \mathrm{wt} \%$ polymer content in $10 \mathrm{mM}$ HEPES buffer and $\mathrm{pH}$ in the 6.6 to 8.0 range, at $25^{\circ} \mathrm{C}$. A $1: 1 \mathrm{MS}$ :thiol ratio was used for the experiments. Preliminary studies based on macroscopic observations indicated that thiol-MS gels at $\mathrm{pH} 6.6$ formed a crosslinked gel within 4 min (see Figure 1d and Table 2). This is a convenient crosslinking time that enables proper mixing and homogenization of precursor solutions. At $\mathrm{pH}$ 6.6, the crosslinked networks reached a shear storage modulus of $\mathrm{G}^{\prime} \sim 1 \mathrm{kPa}$ as measured by rheology (Figure 1d). Note that methanesulfinic acid is formed as byproduct of the crosslinking 
reaction (demonstrated by ${ }^{1} \mathrm{H}$ NMR and mass spectrometry analyses, see details in the Supporting Information, Figure S1 to S3). This aspect will be further addressed later in the manuscript.

Figure 2a compares the crosslinking kinetics of thiol-MS with that of thiol-Mal and thiol-VS systems. Experiments were performed under conditions typically used to prepare thiolmediated gels for cell culture (5 wt $\%$ polymer, in $10 \mathrm{mM}$ HEPES buffer, $\mathrm{pH} 8.0$, at $\left.25^{\circ} \mathrm{C}\right) .{ }^{[12 \mathrm{~b} \text {, }}$ ${ }^{28]}$ Under these conditions, the thiol-MS gel formed in 3-4 s (Table 2). This is a short crosslinking time, though it allowed mixing and homogenization of gel precursors. In comparison, the thiol-Mal gel required $<1 \mathrm{~s}$ for crosslinking and inhomogeneous gels were obtained, while the thiol-VS system showed a gelation time of about $10 \mathrm{~min}$ and took ca $2 \mathrm{~h}$ to complete crosslinking. These results indicate the following trend in gelation rate: thiol-Mal $>$ thiol-MS > thiol-VS, in agreement with reported reaction rates for model compounds, ${ }^{[24,26-}$ ${ }^{27]}$ as shown in Table 1.

The values of the shear modulus of the crosslinked gels after $1 \mathrm{~h}$ were $\mathrm{G}^{\prime}{ }_{25^{\circ} \mathrm{C}}=1700 \mathrm{~Pa}$ for thiol-VS, $700 \mathrm{~Pa}$ for thiol-MS and $480 \mathrm{~Pa}$ for thiol-Mal, respectively (5 wt \%, pH 8.0). The higher shear modulus of thiol-MS vs. thiol-Mal hydrogels is probably due to a higher homogeneity of the former, as consequence of the slower gelation kinetics, enabling better mixing of precursors and leading to less network defects and higher crosslinking degree. This result contradicts previous reactivity studies of thiol-Mal and thiol-MS couplings on small model molecules, which were shown to have similar reaction conversions in phosphate buffer saline (PBS) $\mathrm{pH} 7.4 .{ }^{[23 \mathrm{~b}]}$ We hypothesized that hydrolysis of Mal groups, which occurs at basic $\mathrm{pH}$, could be in part the reason for the lower mechanical properties of thiol-Mal in our studies at $\mathrm{pH}$ 8. To check this hypothesis, the stability of a 4 wt\% PEG-Mal solution in deuterated PBS was studied by ${ }^{1} \mathrm{H}$ NMR. Hydrolysis of Mal groups was detected from 45 min (see Figure S4 and S5 in the SI), confirming that lower shear modulus of thiol-Mal gels could 
be due to Mal hydrolysis. Thiol-VS gels reached the highest shear modulus. We hypothesized that this could be related to a higher conversion or to the slower curing kinetics rendering a network with fewer defects. Similar trend in the crosslinking kinetics was observed at $37^{\circ} \mathrm{C}$ and $\mathrm{pH} 8.0, \mathrm{G}^{\prime}{ }_{37^{\circ} \mathrm{C}}=2700 \mathrm{~Pa}$ for thiol-VS, $1250 \mathrm{~Pa}$ for thiol-MS and $500 \mathrm{~Pa}$ for thiol-Mal after 1 hour reaction time (Figure S6). Altogether, these results show that thiol-MS crosslinking presents intermediate kinetics between the very fast crosslinking thiol-Mal and the slow thiolVS derived materials. The observed crosslinking time in the range of a few seconds allows comfortable mixing and pipetting of the components at low shear forces, and this is expected to be profitable for cell encapsulation. ${ }^{[29]}$ 

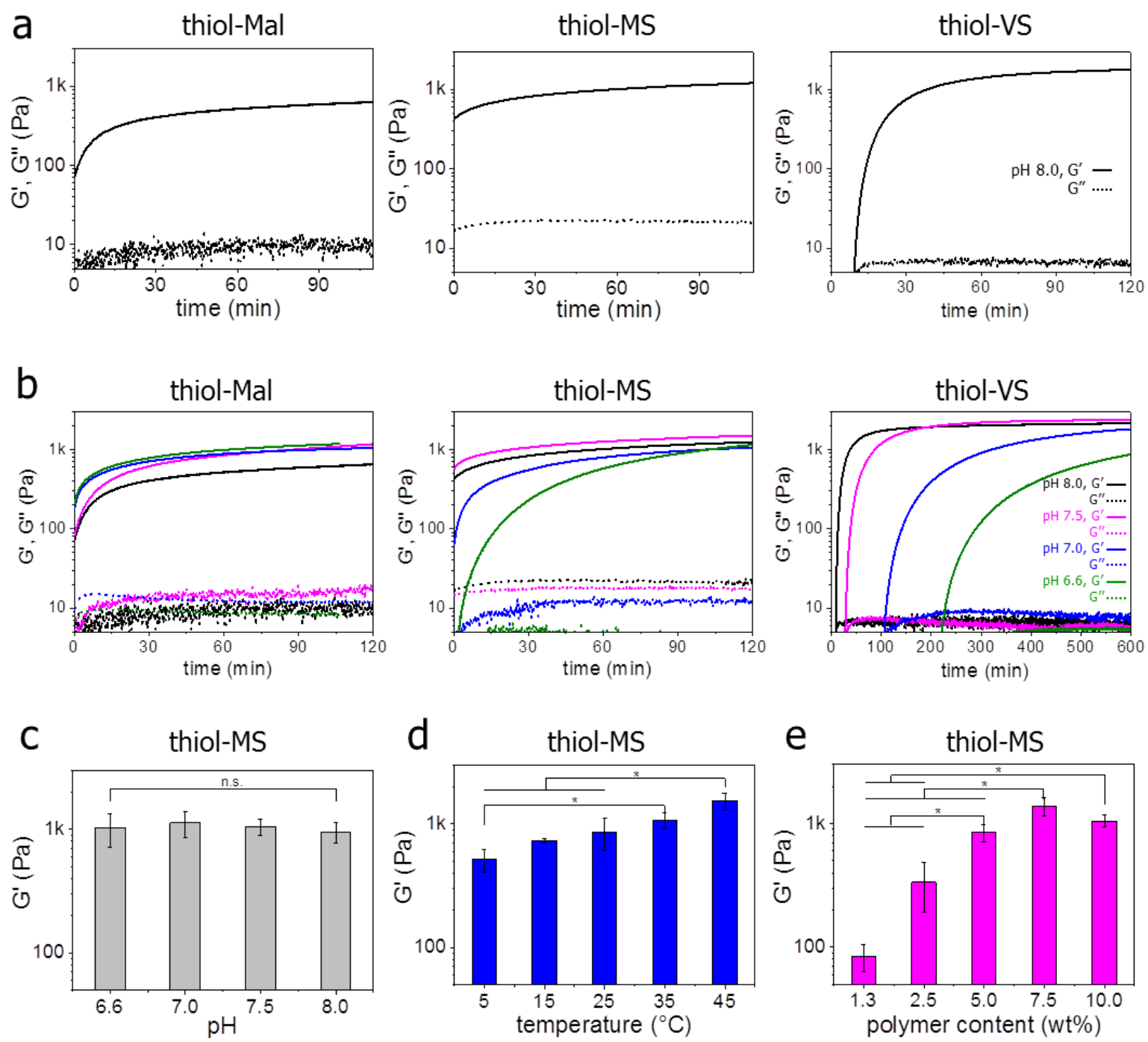

Figure 2. Comparison of gelation kinetics of thiol- $X$ hydrogels under different conditions, as measured by rheology. a) Effect of crosslinking chemistry (at $5 \mathrm{wt} \%$ polymer content, $\mathrm{pH} 8.0$, $T=25^{\circ} \mathrm{C}$ ) and b) effect of $\mathrm{pH}$ (at $5 \mathrm{wt} \%$ polymer content, $T=25^{\circ} \mathrm{C}$ ) on crosslinking kinetics and shear moduli. c) Final shear modulus of thiol-MS gels remains unaffected upon changing $\mathrm{pH}$ (conditions: $5 \mathrm{wt} \%$ polymer content, $T=25^{\circ} \mathrm{C}$, at $2 \mathrm{~h}$ ). d-e) Variation of G' of thiol-MS hydrogels with reaction parameters: d) temperature between 5 and $45{ }^{\circ} \mathrm{C}(5 \mathrm{wt} \%$ polymer content, $\mathrm{pH} 7.0,1 \mathrm{~h}$ reaction time) and e) polymer content between 1.3 and $10 \mathrm{wt} \%(\mathrm{pH} 7.5$, $T=25^{\circ} \mathrm{C}, 1 \mathrm{~h}$ reaction time). Statistical significance analysis was performed by ANOVA followed by post-hoc Tukey test (mean $\pm \mathrm{SD}, * \mathrm{p}<0.05$ was used for statistical significance; n.s. $=$ not significant.) 
Table 2. Gelation time of thiol-X hydrogels at varying $\mathrm{pH}$ values.

\begin{tabular}{|l|l|l|l|l|}
\hline \multirow{2}{*}{ gel $^{\text {a) }}$} & \multicolumn{4}{l|}{$\mathrm{pH}$} \\
\cline { 2 - 5 } & 8.0 & 7.5 & 7.0 & 6.6 \\
\hline thiol-Mal & $<1 \mathrm{~s}$ & $1-2 \mathrm{~s}$ & $2-3 \mathrm{~s}$ & $5-6 \mathrm{~s}$ \\
\hline thiol-MS & $3 \mathrm{~s}$ & $6 \mathrm{~s}$ & $12 \mathrm{~s}$ & $4 \mathrm{~min}$ \\
\hline thiol-VS & $8 \mathrm{~min}$ & $22 \mathrm{~min}$ & $88 \mathrm{~min}$ & $190 \mathrm{~min}$ \\
\hline
\end{tabular}

a) Experiments were performed at $5 \mathrm{wt} \%$ polymer content, in $10 \mathrm{mM}$ HEPES buffer, $T=25^{\circ} \mathrm{C}$. Gelation time was taken as the time elapsed between the mixing of the two components (30 $\mu \mathrm{L}$ each) and the moment when pipetting of the mixture was no longer possible. Size of pipette tip $=2-200 \mu \mathrm{L}, 53 \mathrm{~mm}$.

The reaction rate of the polar thiol-X coupling is dependent on $\mathrm{pH}$ within the $\mathrm{pH}$ range 6 to 9 . This is due to the deprotonation of the thiol group ( $\mathrm{pKa} \sim 8)$, which acts as nucleophile in these reactions. ${ }^{[30]}$ This feature provides an interesting opportunity for $\mathrm{pH}$-controlled curing kinetics within physiologically relevant conditions. Thiol-MS crosslinking within $\mathrm{pH}$ interval of 8.0-6.6 was studied. Remarkably, the $\mathrm{pH}$ change from 8.0 to 6.6 allowed slowing of the gelation process from a few seconds to a couple of minutes (Figure $2 b$, Table 2), providing an ideal experimental time window for 3D cell encapsulation applications. In contrast, thiol-Mal gelation time only varied within a few seconds, while thiol-VS ranged from a few minutes to a couple of hours in the same $\mathrm{pH}$ range (Figure $2 \mathrm{~b}$, Table 2). These results highlight the advantages of thiol-MS gels in terms of handling and adaptability to application specifications versus the thiol-Mal and thiol-VS as established, state-of-the-art formulations.

The final shear modulus of thiol-MS crosslinked hydrogels remained unaffected by the working $\mathrm{pH}$ in the interval $\mathrm{pH}=8.0-6.6$ (Figure $2 \mathrm{c}$ and $\mathrm{S} 7, \mathrm{G}^{\prime}$ after $2 \mathrm{~h}$ of gelation ca $1 \mathrm{kPa}$ ). This proves that the handling of thiol-MS gels can be tuned with $\mathrm{pH}$ without changing materials properties and without compromising the final stability of the gel. In comparison, thiol-Mal system showed a drop in $\mathrm{G}^{\prime}$ at $\mathrm{pH} 8.0$ but similar final shear modulus at $\mathrm{pH}=7.5$ 6.6 (Figure S8), while thiol-VS showed a clear trend of slower gelation kinetics and decreased shear modulus with decreasing $\mathrm{pH}$ (Figure S9). 
The dependence of gelation kinetics and shear modulus of thiol-MS gels with gelation temperature and polymer concentration was also studied. A temperature decrease from $45^{\circ} \mathrm{C}$ to $5^{\circ} \mathrm{C}$ allowed a decrease in shear modulus from 1540 to $520 \mathrm{~Pa}$ (Figure $2 \mathrm{~d}$ and $\mathrm{S} 10$, measured at $\mathrm{pH} 7.0,1 \mathrm{~h}$ reaction time) and an increase in the gelation time from 7 to $30 \mathrm{~s}$ (Table S1). Increasing polymer content from 1.3 to $10 \mathrm{wt} \%$ led to shortening of the gelation time from 18 to $2 \mathrm{~s}$ (Figure 2e and Table 2, measured at $\mathrm{pH} 7.5$ and $25^{\circ} \mathrm{C}$ ). The increase of the polymer content raises the probability of reaction partners to form the new crosslinks and increases the reaction rate. G' also increased from 85 to $1400 \mathrm{~Pa}$ with an increase in the polymer concentration from 1.3 to $7.5 \mathrm{wt} \%$ and, surprisingly, slightly dropped for polymer concentration of $10 \mathrm{wt} \%$. This result was surprising, since mixing of the $10 \mathrm{wt} \%$ precursor mixture appeared to be uncomplicated and no inhomogeneity issues were expected. To get a deeper insight, we measured the $\mathrm{pH}$ of the resulting gels (see Figure $\mathrm{S} 11 \mathrm{a}$ ). We found that the $\mathrm{pH}$ of the thiol-MS gels after polymerization decreased with increasing polymer concentration. Gels between 1.3-7.5 wt \% showed a pH between 7.5-6.5, while gels at $10 \mathrm{wt} \%$ had a $\mathrm{pH}$ around 5.1. Note that the $\mathrm{pH}$ of the mixture was buffered at $10 \mathrm{mM}$ HEPES in all cases. The drop in $\mathrm{pH}$ during gelation can be explained by the release of methanesulfinic acid as leaving group during thiol-MS coupling (Figure S1 to S3). At high polymer content (10\%), the leaving group is produced at higher concentration, leading to an acidic $\mathrm{pH}$ of the crosslinking reaction and, consequently, to lower crosslinking degree and final shear modulus value. This effect could be avoided by increasing the buffer capacity of the crosslinking medium. Using $50 \mathrm{mM}$ HEPES buffer concentration and increasing polymer content from 1.3-10 wt $\%$ resulted in increased $\mathrm{G}^{\prime}$ from 100 to $1300 \mathrm{~Pa}$ while the $\mathrm{pH}$ of the gels varied from 7.3 to 6.8 (Figure S11b). Note that these conditions are also cytocompatible (see Figure S13 and Ref $\left.{ }^{[31]}\right)$. 
Table 3. Swelling ratio in water of thiol-X hydrogels.

\begin{tabular}{|l|l|l|}
\hline \multirow{2}{*}{ gel $^{\text {a) }}$} & \multicolumn{2}{|l|}{ swelling ratio (SR) } \\
\cline { 2 - 3 } & {$[\mathrm{mg}$ water per mg gel] } & relative value \\
\hline thiol-Mal & $77.1 \pm 3.0$ & 1.7 \\
\hline thiol-MS & $46.0 \pm 2.8$ & 1.0 \\
\hline thiol-VS & $49.3 \pm 1.4$ & 1.1 \\
\hline
\end{tabular}

a) Conditions: $5 \mathrm{wt} \%$ polymer content; $n=3$.

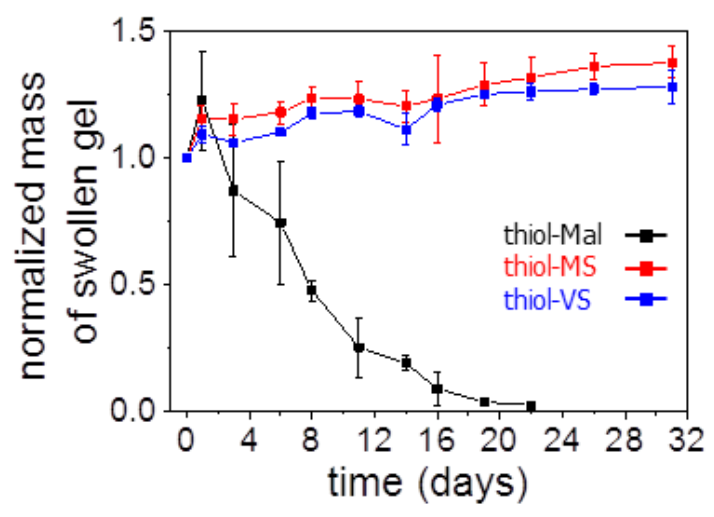

Figure 3. Hydrolytic stability of thiol-X gels. Gels (prepared at $5 \mathrm{wt} \%$ polymer content, $n=3$ ) were incubated in cell culture medium at $37^{\circ} \mathrm{C}$ for $>4$ weeks and the mass of the swollen gel was measured.

The swelling ratio (SR) of $5 \mathrm{wt} \%$ thiol-MS gels was measured in water. A swelling of $46.0 \pm$ $2.8 \mathrm{mg}$ water per mg polymer was obtained (Table 3 ). Thiol-VS gels displayed similar SR values, while thiol-Mal swelled ca 1.7-fold more. The higher swelling of thiol-Mal gels agrees with their lower crosslinking degree revealed by the rheology measurements. The similar swelling values of thiol-MS and thiol-VS gels, inspite of lower crosslinking degree of thiolMS gels, can be explained by the hydrophobic character of the aromatic thioether crosslinks in thiol-MS gels.

The hydrolytic stability is a relevant material property for hydrogels designed for 3D cell culture. Stability experiments with $5 \mathrm{wt} \%$ thiol-X gels were performed by gravimetric 
analysis of gels after incubation in cell culture medium (RPMI, containing FBS) at $37^{\circ} \mathrm{C}$ for $>4$ weeks (Figure 3). The mass of swollen thiol-MS gels reached 1.2 times the initial mass during the first 2 weeks and 1.4 times at the week 4, indicating little gel erosion and high hydrolytic stability of the thiol-MS gel system. Note that the long-term stability of the gels is advantageous for long term cell culture, and allows specific tuning of degradation kinetics by copolymerization with degradable peptides. ${ }^{[12 b]}$ The stability of thiol-MS system was similar to that of thiol-VS, which is typically used for long term cultures, ${ }^{[12 \mathrm{a}]}$ and much higher than the stability of thiol-Mal gels (1.2-fold swelling in 2 days followed by hydrogel disintegration at day 18). ${ }^{[32]}$ The hydrolysis of thiol-Mal gels is related to the low stability of the thioether succinimide bond, which undergoes retro-Michael and exchange reactions in presence of other soluble thiols existing in cell culture media. ${ }^{[18]}$ Our results are in agreement with reported studies on model MS compounds, showing superior stability of thio-heteroaromatic conjugates resulting from thiol-MS coupling versus thiol-Mal ones under physiological conditions. ${ }^{[23 \mathrm{~b}]}$ Thiol-MS gels with $10 \mathrm{wt} \%$ polymer content remained hydrolytically stable over $>6$ weeks (results not shown).

Thiol-MS hydrogels were tested as matrices for cell encapsulation. We followed reported protocols used for 3D cell encapsulation with thiol-Mal gels. ${ }^{[12 b, 28]}$ The PEG-MS precursor was first incubated with the cell adhesive cyclo(RGDfC) peptide, then mixed with L929 fibroblasts, and finally mixed with an enzymatically cleavable dithiol peptide (VPM) as crosslinker. A composition of $4 \mathrm{wt} \%$ PEG-MS, $1 \mathrm{mM}$ RGD peptide and $3.14 \mathrm{mM}$ VPM was used. ${ }^{[12 b, 28]}$ Upon mixing, the solution remained low viscous for a few seconds, enabling homogenization by pipetting at low shear forces. A stable gel formed within $15 \mathrm{~min}$, as visualized by naked eye. The distribution of the cells within the hydrogel was analyzed by Zstack imaging at a confocal microscope. A uniform distribution of cells across the thickness of the hydrogel was observed (Figure 4a). Live/dead assays performed on cells encapsulated for 
1 day into thiol-MS gels proved the cytocompatibility of our material (>90\% viability, Figure $4 \mathrm{~b}$ and c). These results indicate that the crosslinking kinetics of PEG-MS system is very convenient for obtaining homogeneous constructs at physiological and cytocompatible experimental conditions. Achieving a homogeneous cell density within an artificial matrix is relevant for modulating the behavior of delivered cells, for example, in injectable systems. ${ }^{[15]}$ Similar experiments performed with thiol-Mal hydrogels resulted in immediate curing upon mixing of the precursors, impeding homogenization and leading to cell agglomeration at the upper part of the gel (Figure 4a). On the other hand, the thiol-VS system allowed for adequate mixing, but the slow gelation kinetics lead to cell sedimentation at the bottom of the gel during the curing time (Figure 4a). These results are in line with previous reports by Peyton et $\mathrm{al}^{[17 \mathrm{a}]}$ on the effect of crosslinking rate on the distribution of fluorescent beads encapsulated into thiol-Mal hydrogels, and by Shikanov et $\mathrm{al}^{[19]}$, who indicated the need of flipping around thiol-VS gels during curing to avoid cell settling. In this context, thiol-MS hydrogels show ideal kinetics and overcome these inconveniences. Cells embedded in thiol-MS hydrogels after 3 days of culture remained homogeneously distributed and showed less clustering than in the other two systems (see Figure S12).

In order to prove that cells cultured in thiol-MS hydrogels remained functional, a migration assay was performed. L929 fibroblast spheroids were encapsulated in the degradable thiol-MS hydrogels, ${ }^{[28]}$ cultured for 3 days, fixed and stained. Cell migration distance from the spheroid was quantified as an indication for invasiveness through 3D hydrogels. Cell motility in 3D matrices is reported to decrease with a decrease in pore size of the gel or with an increase in network crosslinking and matrix hydrolytic stability. ${ }^{[33]}$ Cells in the encapsulated spheroid remained viable, recognized the RGD ligand bound to the matrix, enzymatically hydrolyzed the gel network and actively migrated through 3D thiol-MS hydrogels. They covered a distance of $\mathrm{d} \sim 425 \pm 38 \mu \mathrm{m}$ after 3 days of culture (Figure $4 \mathrm{~d}$ and $\mathrm{f}$ ). We compared these 
results with those obtained for thiol-Mal and thiol-VS as materials for 3D cell encapsulation. The migration distance was $\sim 470 \pm 55 \mu \mathrm{m}$ for thiol-Mal and $\sim 360 \pm 48 \mu \mathrm{m}$ for thiol-VS systems, respectively (Figure 4f). This result can be attributed to the differences in the gel shear storage modulus (note that $\mathrm{G}^{\prime}{ }_{37^{\circ} \mathrm{C}}=\mathrm{VS}>\mathrm{MS}>\mathrm{Mal}$, as shown in Figure $\mathrm{S6}$ ) and in the hydrolytic stability (MS=VS $>>$ Mal, Figure 3). A lower crosslinking density and a faster degradation turn the matrix more invasive by cells, ${ }^{[34]}$ and lead to longer migrated distances. Altogether, our results demonstrate the potential of novel thiol-MS hydrogels as valuable alternative biomaterial for 3D cell encapsulation. 


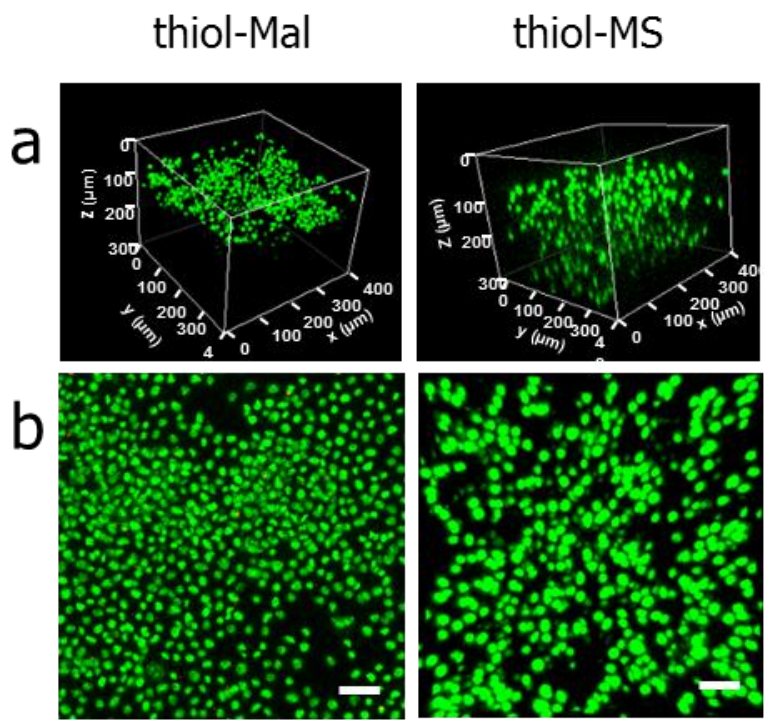

\section{thiol-VS}
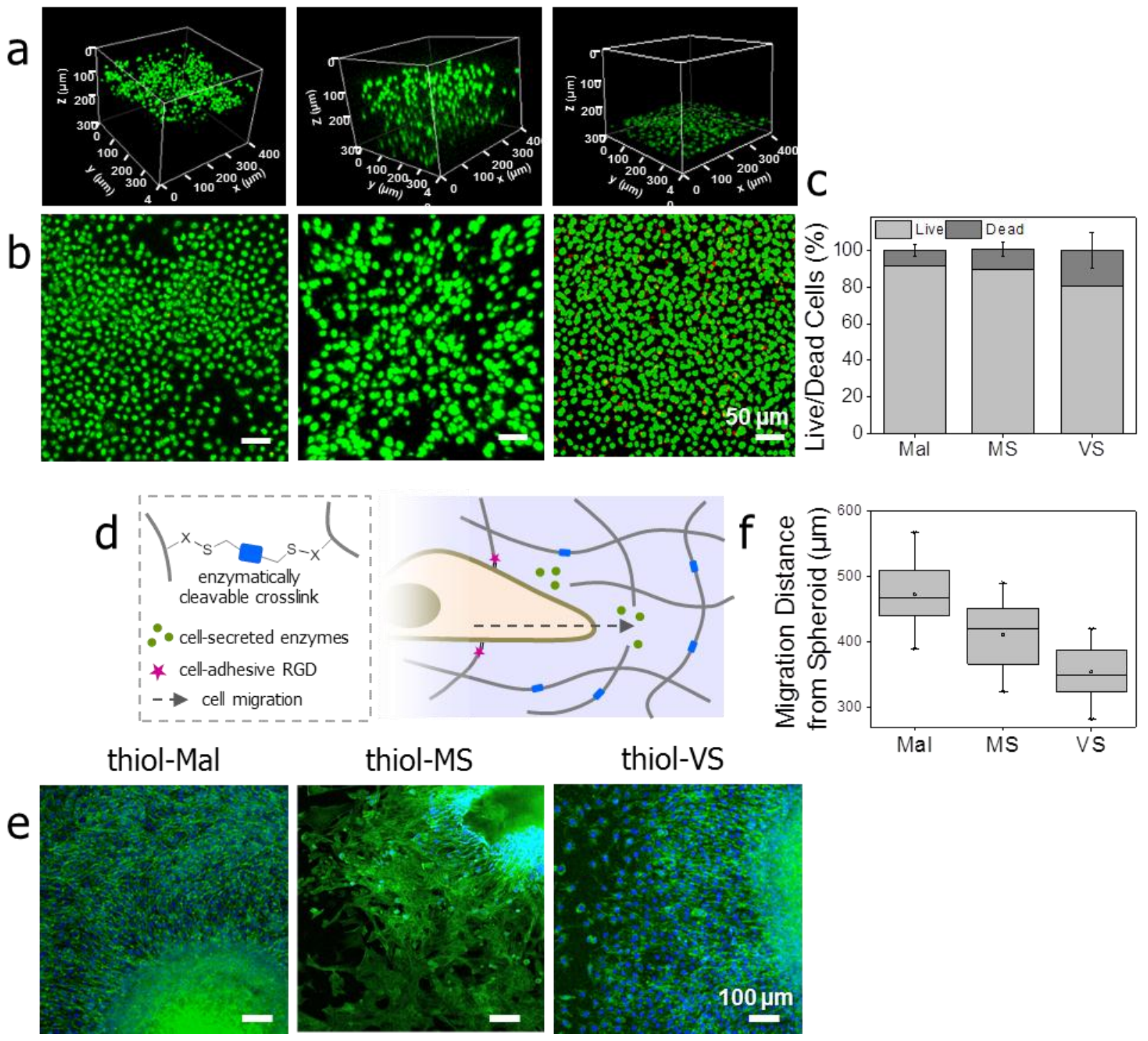

Figure 4. L929 fibroblast encapsulated in enzymatically cleavable thiol-X PEG hydrogels. a,b) Z-stack fluorescence images of a live (green)/dead (red) assay of fibroblasts encapsulated for 1 day in the hydrogels. c) Quantification of cell viability. d) Schematics of enzymatically cleavable gels used for encapsulation of cell spheroids. e) Fluorescence images of cells migrating out of encapsulated spheroids after 3 days of culture. Green: FITC-phalloidin (actin fibers), blue: DAPI (nucleus). f) Quantification of migration distance from e).

\section{Conclusions}

The thiol-MS reaction is suitable for crosslinking hydrogels and for cell-encapsulation. This reaction presents intermediate kinetics between thiol-Mal and thiol-VS systems and proceeds at high conversion. The resulting reaction product has good hydrolytic stability and cytocompatibility. Under aqueous mild conditions, the thiol-MS reaction is orthogonal to 
alcohols, amines, carboxylic acids and acrylate functional groups, ${ }^{[23 a, 25 a, 25 b]}$ which allows the application of this crosslinking mechanism to almost any natural polymeric backbone of interest in the biomedical field. The reactivity of thiol-MS pair can be regulated by the working $\mathrm{pH}$ and by selecting different MS aromatic substrates. ${ }^{[23 \mathrm{~b}]}$ All these properties together make thiol-MS a superior alternative to thiol-MA and thiol-VS for 3D cell encapsulation. Beyond 3D culture applications, thiol-MS chemistry can be envisioned as an efficient way of generating supporting matrices for implantable or injectable cell therapy constructs of clinical interest.

\section{Acknowledgements}

The authors thank Dr. Josef Zapp (Saarland University) and Dr. Judith Hoffmann (HIPS) for their help with 500-MHz NMR measurements; Ms. Rebecca Ludwig for technical assistance in organic synthesis of precursors, MSc. Maria Villiou for Figure S13, Dr. Claudia FinkStraube and Mrs. Ha Rimbach-Nguyen (Chemical Analytics) for mass spectrometry measurements; as well as Dr. Roshna Vakeel and Dr. Samuel Pearson (INM) for constructive discussions. We are grateful to the European Union's Horizon 2020 research and innovation programme under the FET PROACTIVE grant agreement no. 731957 (Mechano-Control) and to DFG (Project no. 422041745) for their financial support.

\section{Conflict of interest}

There are no conflicts of interest to declare. 


\section{References}

[1] a) C. M. Madl, S. C. Heilshorn, Adv. Funct. Mater. 2018, 28, 1706046; b) S. A. Fisher, A. E. G. Baker, M. S. Shoichet, J. Am. Chem. Soc. 2017, 139, 7416.

[2] C. A. Durst, M. P. Cuchiara, E. G. Mansfield, J. L. West, K. J. Grande-Allen, Acta Biomater. 2011, 7, 2467.

[3] K. W. M. Boere, M. M. Blokzijl, J. Visser, J. E. A. Linssen, J. Malda, W. E. Hennink, T. Vermonden, J. Mater. Chem. B 2015, 3, 9067.

[4] a) Y.-H. Ma, J. Yang, B. Li, Y.-W. Jiang, X. Lu, Z. Chen, Polym. Chem. 2016, 7, 2037; b) D. D. McKinnon, D. W. Domaille, J. N. Cha, K. S. Anseth, Adv. Mater. 2014, 26, 865; c) G. N. Grover, J. Lam, T. H. Nguyen, T. Segura, H. D. Maynard, Biomacromolecules 2012, 13, 3013.

[5] C. A. DeForest, B. D. Polizzotti, K. S. Anseth, Nat. Mater. 2009, 8, 659.

[6] L. J. Smith, S. M. Taimoory, R. Y. Tam, A. E. G. Baker, N. Binth Mohammad, J. F. Trant, M. S. Shoichet, Biomacromolecules 2018, 19, 926.

[7] D. L. Alge, M. A. Azagarsamy, D. F. Donohue, K. S. Anseth, Biomacromolecules 2013, 14, 949.

[8] J. H. Cho, J. S. Lee, J. Shin, E. J. Jeon, S. An, Y. S. Choi, S.-W. Cho, Adv. Funct. Mater. 2018, 28, 1705244.

[9] J. P. Jung, A. J. Sprangers, J. R. Byce, J. Su, J. M. Squirrell, P. B. Messersmith, K. W. Eliceiri, B. M. Ogle, Biomacromolecules 2013, 14, 3102.

[10] X.-H. Qin, X. Wang, M. Rottmar, B. J. Nelson, K. Maniura-Weber, Adv. Mater. 2018, 30,1705564 .

[11] A. Skardal, M. Devarasetty, H.-W. Kang, I. Mead, C. Bishop, T. Shupe, S. J. Lee, J. Jackson, J. Yoo, S. Soker, A. Atala, Acta Biomater. 2015, 25, 24.

[12] a) M. P. Lutolf, G. P. Raeber, A. H. Zisch, N. Tirelli, J. A. Hubbell, Adv. Mater. 2003, 15, 888; b) E. A. Phelps, N. O. Enemchukwu, V. F. Fiore, J. C. Sy, N. Murthy, T. A. 
Sulchek, T. H. Barker, A. J. García, Adv. Mater. 2012, 24, 64; c) L. J. Macdougall, M. M. Pérez-Madrigal, M. C. Arno, A. P. Dove, Biomacromolecules 2018, 19, 1378; d) P. M. Kharkar, K. L. Kiick, A. M. Kloxin, Polym. Chem. 2015, 6, 5565.

[13] a) D. L. Alge, K. S. Anseth, in Thiol-X Chemistries in Polymer and Materials Science, The Royal Society of Chemistry 2013, p. 165; b) D. P. Nair, M. Podgórski, S. Chatani, T. Gong, W. Xi, C. R. Fenoli, C. N. Bowman, Chem. Mater. 2014, 26, 724; c) P. M. Kharkar, M. S. Rehmann, K. M. Skeens, E. Maverakis, A. M. Kloxin, ACS Biomater. Sci. Eng. 2016, 2, 165.

[14] J. Su, Gels 2018, 4, 72.

[15] L. Haines-Butterick, K. Rajagopal, M. Branco, D. Salick, R. Rughani, M. Pilarz, M. S. Lamm, D. J. Pochan, J. P. Schneider, Proc. Natl. Acad. Sci. U.S.A. 2007, 104, 7791.

[16] a) M. Patenaude, S. Campbell, D. Kinio, T. Hoare, Biomacromolecules 2014, 15, 781; b) M. Patenaude, N. M. B. Smeets, T. Hoare, Macromol. Rapid Commun. 2014, 35, 598.

[17] a) L. E. Jansen, L. J. Negrón-Piñeiro, S. Galarza, S. R. Peyton, Acta Biomater. 2018, 70, 120; b) N. J. Darling, Y. S. Hung, S. Sharma, T. Segura, Biomaterials 2016, 101, 199.

[18] a) S. C. Alley, D. R. Benjamin, S. C. Jeffrey, N. M. Okeley, D. L. Meyer, R. J. Sanderson, P. D. Senter, Bioconjugate Chem. 2008, 19, 759; b) A. D. Baldwin, K. L. Kiick, Bioconjugate Chem. 2011, 22, 1946.

[19] J. Kim, Y. P. Kong, S. M. Niedzielski, R. K. Singh, A. J. Putnam, A. Shikanov, Soft Matter 2016, 12, 2076.

[20] a) M. P. Lutolf, J. A. Hubbell, Biomacromolecules 2003, 4, 713; b) P. M. Kharkar, A. M. Kloxin, K. L. Kiick, J. Mater. Chem. B 2014, 2, 5511.

[21] S. A. Stewart, M. B. Coulson, C. Zhou, N. A. D. Burke, H. D. H. Stöver, Soft Matter 2018, 14, 8317. 
[22] D. M. Headen, J. R. García, A. J. García, Microsyst. Nanoeng. 2018, 4, 17076.

[23] a) D. Zhang, N. O. Devarie-Baez, Q. Li, J. R. Lancaster, M. Xian, Org. Lett. 2012, 14, 3396; b) N. Toda, S. Asano, C. F. Barbas, Angew. Chem., Int. Ed. 2013, 52, 12592.

[24] X. Chen, H. Wu, C.-M. Park, T. H. Poole, G. Keceli, N. O. Devarie-Baez, A. W. Tsang, W. T. Lowther, L. B. Poole, S. B. King, M. Xian, C. M. Furdui, ACS Chem. Biol. 2017, 12, 2201.

[25] a) A. Farrukh, J. I. Paez, M. Salierno, A. del Campo, Angew. Chem. Int. Ed. 2016, 55, 2092; b) A. Farrukh, J. I. Paez, M. Salierno, W. Fan, B. Berninger, A. del Campo, Biomacromolecules 2017, 18, 906; c) J. I. Paez, A. Farrukh, O. Ustahüseyin, A. del Campo, in Biomaterials for Tissue Engineering: Methods and Protocols (Ed: K. Chawla), Springer New York, New York, NY 2018, p. 101.

[26] F. Saito, H. Noda, J. W. Bode, ACS Chem. Biol. 2015, 10, 1026.

[27] H. Wang, F. Cheng, M. Li, W. Peng, J. Qu, Langmuir 2015, 31, 3413.

[28] A. Farrukh, J. I. Paez, A. del Campo, Adv. Funct. Mater. 2019, 29, 1807734.

[29] H. J. Kong, M. K. Smith, D. J. Mooney, Biomaterials 2003, 24, 4023.

[30] M. H. Stenzel, ACS Macro Lett. 2013, 2, 14.

[31] S. H. Chen, A. Chao, C. L. Tsai, S. C. Sue, C. Y. Lin, Y. Z. Lee, Y. L. Hung, A. S. Chao, A. J. Cheng, H. S. Wang, T. H. Wang, Mol. Ther.- Methods Clin. Dev. 2019, 13, 99.

[32] N. Boehnke, C. Cam, E. Bat, T. Segura, H. D. Maynard, Biomacromolecules 2015, 16, 2101.

[33] P.-H. Wu, D. M. Gilkes, D. Wirtz, Annu. Rev. Biophys. 2018, 47, 549.

[34] M. P. Lutolf, J. L. Lauer-Fields, H. G. Schmoekel, A. T. Metters, F. E. Weber, G. B. Fields, J. A. Hubbell, Proc. Natl. Acad. Sci. U.S.A. 2003, 100, 5413. 